\title{
REMOTE SENSING FOR DETECTING AND DISTINGUISHING MOISTURE AND NITROGEN STRESS IN MAIZE
}

\author{
Elmetwalli, A. H.
}

\begin{abstract}
Remote sensing has been known as a robust technique in precision farming over the last quarter of the $20^{\text {th }}$ century. It has been successfully used to asses many biophysical and biochemical properties of various crops. Detecting stress in crops at an early growth stage is important to limit crop reductions and therefore increasing productivity. Thus, remote sensing may be a valuable tool for precision farming in cereal production. The present study was conducted to investigate the effectiveness of broad band and hyperspectral remotely sensed data to quantify maize (Zea maize L.) grain yield under moisture and nitrogen deficiency stresses. The results demonstrated strong significant correlations between various crop properties and some vegetation indices. RVI, SAVI, OSAVI and $R_{750} / R_{550}$ were found to be sensitive to maize grain yield $(r>0.80)$. The correlations with grain yield were found to be strongest at the grain filling stage. Penalized Linear Discrimnant Analysis (PLDA) and Principle Component Analysis (PCA) demonstrated the possibility to distinguish between moisture and nitrogen deficiency stress.
\end{abstract}

Key words: Remote sensing, Reflectance, nitrogen deficiency, moisture, stress

\section{INTRODUCTION}

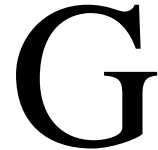
lobally, water is considered as the main limiting factor that reduces crop productivity especially in arid and semi-arid regions. Paolo and Rinaldi (2008) investigated maize yield response to irrigation and nitrogen fertilization and concluded that maize productivity is highly dependent on irrigation supplies in particular in areas with water limited conditions. They also reported that irrigation was more effective than nitrogen in increasing grain yield in two successive years. Increasing water deficiency reduced the photochemical activity of chlorophyll (Souza et al., 2004). Drought and low soil fertility are the most stresses threatening maize production in eastern and southern Africa (Banziger and Diallo, 2004).

Assi. Prof., Agric. Eng. Dept., Fac. of Agric., Tanta Univ., Egypt. 
Nitrogen (N) is the most important element affecting crop grain yield and is the most limiting nutrient in crop production as cropping practices become more intensive, other nutrients will likely become limiting as well (Osborne et al. 2002). When plants are subjected to nitrogen stress the first symptom tends to be yellowing of leaves. Using methods of plant-based measurements to detect crop status such as canopy temperature are very time consuming and requires a huge number of observations to characterize a field (Osborne et al., 2002).

Applying remote sensing technique in the field of precision farming becomes crucial as a result of limited natural resources. The advances in remote sensing sensors technology can enhance monitoring techniques in precision farming. Concentration of photosynthetic pigments within leaves tend to be the first parts of plants to respond to stress. Leaf pigments such as chlorophylls, xanthophylls and carotenoids strongly absorb light in the photosynthetically active portion of the electromagnetic spectrum (Prasad et al., 2007) and therefore strongly affect the spectral reflectance characteristics of plant leaves and canopies (Araus et al., 2001). Subsequently, the spectral reflectance characteristics of plant leaves and/or canopies can be used to monitor foliar pigment concentrations and thereby obtain a better understanding of crop health status. Previous studies have documented the effectiveness of spectral reflectance indices derived from remotely sensed data for the detection of stress in vegetation. These include for example, the estimation of chlorophyll $a$ concentration (Ciganda et al., 2009), the identification of plant disease (Zhang et al., 2012), salinity induced stress (Elmetwalli, 2008), nitrogen deficiency (Hong et al., 2007) and moisture stress (Tilling et al., 2007). In plants the concentration of chlorophyll in leaves is strongly related to $\mathrm{N}$ status. Abd-Elrahman et al. (2010) employed in situ spectroscopy data to detect nitrogen deficiency in sugarcane and documented the effectiveness of this technique to predict sugarcane leaf nitrogen. The ability to measure spatial variability in canopy chlorophyll concentration through remote sensing therefore allows the $\mathrm{N}$ status of crops to be assessed rapidly across large field systems (Daughtry et al., 2000). Other studies have demonstrated the ability to predict crop grain yield from remotely sensed data (Babar et al., 2006; Prasad et al., 2007; Weber et al., 2012). Increased efforts are therefore needed to detect the effects of moisture and nitrogen induced stress in maize to limit crop reduction and therefore 
increase productivity. However, much of the published research focused on the remote detection of moisture and nitrogen stress at the leaf scale and often the effects on canopy structure are given little attention. Measurements at the canopy scale are arguably important for evaluating the potential successful implementation of airborne or satellite remote sensing in precision agriculture. In this research, the remote detection of the combined effects of moisture and nitrogen deficiency stress on maize crop health and productivity at both leaf and canopy scales is investigated.

The specific objectives of this research were to; (1) assess the relationship between maize crop properties and both moisture and nitrogen stressors (2) identify the optimum vegetation index to predict maize grain yield and (3) investigate the possibility of distinguishing moisture and nitrogen deficiency stresses spectrally.

\section{MATERIAL AND METHODS}

A field experiment of maize was conducted at North Eltahreer district, Bohaira Governorate in the summer season of 2009. Maize (single cross 10) was sown during the second week of May. The soil at this site is a sandy loam soil with low nitrogen concentration. Maize seeds were sown at a rate of 33000 seeds per feddan (the recommended rate). Phosphorus and potassium were applied to all plots at 60 and $60 \mathrm{~kg}$ per feddan. The total amount of phosphorus and potassium was applied during soil preparation. Four different irrigation regimes at 90, 75, 50 and 25\% AW (available water) were used to subject plants to different levels of moisture stress and four different nitrogen fertilization rates of $0,100,250$ and $300 \mathrm{~kg} \mathrm{~N}$ per feddan were used to subject maize crop to different nitrogen deficiency levels. Different combinations of both moisture and nitrogen levels were also used. The experiment was designed as a split plot design with three replicates. Irrigation treatments were assigned as main plots and nitrogen treatments as subplots. Nitrogen was applied in two equal doses at 30 and 50 days after sowing. Maize grain yield was identified for each treatment at harvesting. An area of $4 \mathrm{~m}^{2}$ was harvested for each treatment and then converted to $\mathrm{Mg} / \mathrm{ha}$.

\section{Reflectance Spectra acquisition, processing and analysis}

An ASD FieldSpec hand held spectroradiometer with a $3.5^{\circ}$ field of view foropic was used to measure the spectral reflectance from plant canopies and leaves. The spectroradiometer was mounted at the end of a telescopic pole at 
a constant height of $2 \mathrm{~m}$ from the soil surface to maximize the scanning area and was increased to 2.5 at the flowering stage onwards. The instrument has a spectral range of $350-050 \mathrm{~nm}$ which was interpolated to a final spectral resolution of $0.5 \mathrm{~nm}$. Reflectance spectra of plant canopies were collected regularly under solar radiation between 11:00 and 15:00 h GMT. Reflectance measurements were collected from early growth stages before applying different moisture and nitrogen deficiency treatments and were then repeated periodically over the growing season until harvest time. The instrument was calibrated to reflectance using a white spectralon reference panel. Ten spectra were acquired from each treatment and the mean spectral was calculated. The spectra were smoothed by passing a $5 \mathrm{~nm}$ running mean filter over the spectrum and truncated between 400 and $900 \mathrm{~nm}$. The spectra were then used to calculate broad band and hyperspectral vegetation indices as detailed in Table 1. Different crop properties were recorded at different growth stages concurrent with the acquisition of spectral reflectance.

Table 1 Examples of spectral vegetation indices calculated from in situ and laboratory darkroom spectroradiometery

\begin{tabular}{|c|c|}
\hline Notation & Formulae \\
\hline NDVI & (NIR-Red)/(NIR+Red) \\
\hline RVI & NIR/Red \\
\hline SAVI & $(\mathrm{NIR}+\mathrm{Red}+\mathrm{L})]^{*}(1+\mathrm{L})$ \\
\hline $\mathrm{GNDVI}_{\mathrm{br}}$ & (NIR-green)/ (NIR+green) \\
\hline DVI & NIR-Red \\
\hline SR & NIR/Red \\
\hline SLAVI & NIR/(Red+NIR) \\
\hline OSAVI & {$[(\mathrm{NIR}-\mathrm{Red}) /(\mathrm{NIR}+\mathrm{Red}+\mathrm{L})]^{*}(1+\mathrm{L}), \mathrm{L}=0.16$} \\
\hline VI1 & NIR/(green-1) \\
\hline RDVI & $\sqrt{N D V \times D V I}$ \\
\hline SI & Red/NIR \\
\hline IPVI & NIR/(NIR+Red) \\
\hline
\end{tabular}

NDVI, Normalized Difference Vegetation Index; RVI, Ratio Vegetation Index; SAVI, Soil Adjusted Vegetation Index; GNDVI, Green Normalized Difference Vegetation Index; DVI, Difference Vegetation Index; SR, Simple Ratio; SLAVI, Specific Leaf Area Vegetation Index; OSAVI, Optimized Soil Adjusted Vegetation Index; VI1, Vegetation Index One; RDVI, Renormalized Difference Vegetation Index; SI, Stress Index; IPVI, Infra-Red Percentage Vegetation Index 


\section{Statistical analysis}

Minitab v14 was used to perform one and two way analysis of variance (ANOVA) to establish significant differences in maize responses to moisture and nitrogen deficiency stress. Data were checked for normality using Anderson-Darling method with a 95\% significance level. The Pearson Product Moment correlation coefficient was used to test the association between different vegetation indices and crop yield and to identify optimum vegetation indices for predicting yield. Simple linear regression analysis was used to derive regression equations to predict grain yield from reflectance spectra.

To distinguish moisture and nitrogen deficiency stresses spectrally, the mean of ten scans was obtained per spectra recorded. This was repeated three times for different replicates and the overall mean for individual treatments was then calculated and used in the Principle Component Analysis (PCA) to initially be used to explore differences in the spectral response from healthy and stressed treatments. Subsequently, PLDA was performed to determine if spectral response of plants could be used to predict the source of stress (i.e. moisture or nitrogen deficiency stress). PLDA was performed on the full spectra datasets using the mda package.

\section{RESULTS AND DISCUSSION}

\section{Effects of moisture and nitrogen deficiency stress on maize grain yield}

The results are illustrated in Figures 1 and 2 and detailed in Table 2. The results demonstrated that both nitrogen deficiency and moisture significantly affected maize grain yield. Moisture stress strongly reduced grain yield $\left(\mathrm{R}^{2}=\right.$ $0.90, \mathrm{p}<0.005)$. The highest grain yield of $8.2 \mathrm{Mg} / \mathrm{ha}$ was recorded with the control treatment whilst the lowest grain yield of $1.4 \mathrm{Mg} / \mathrm{ha}$ was recorded with the treatment received $25 \%$ FC moisture regime and $0 \mathrm{~N}$. Nitrogen deficiency also significantly affected maize grain yield. Significant decreases in maize grain yield were observed with increasing nitrogen deficiency levels. Maize grain yield fell to about $17 \%$ of the maximum value when subjected to the lowest watering regime and the highest nitrogen deficiency level.

\section{Regression analysis}

The regression analysis showed a significant linear relationship between maize grain yield and moisture regime $\left(\mathrm{R}^{2}=0.90 ; \mathrm{p}<0.005\right)$ as shown in 
Figure 1. This indicates that yield reductions were highest in treatments with the lowest watering regimes $(25 \%$ FC). A further significant linear relationship was found between maize grain yield and nitrogen deficiency levels $\left(R^{2}=0.97 ; p<0.005\right)$ as shown in Figure 1 indicating that grain yield reductions were greater at the highest nitrogen deficiency levels (zero nitrogen). The results therefore demonstrated that regression analysis showed significant relationships between maize grain yield and both moisture and nitrogen deficiency for all trails.
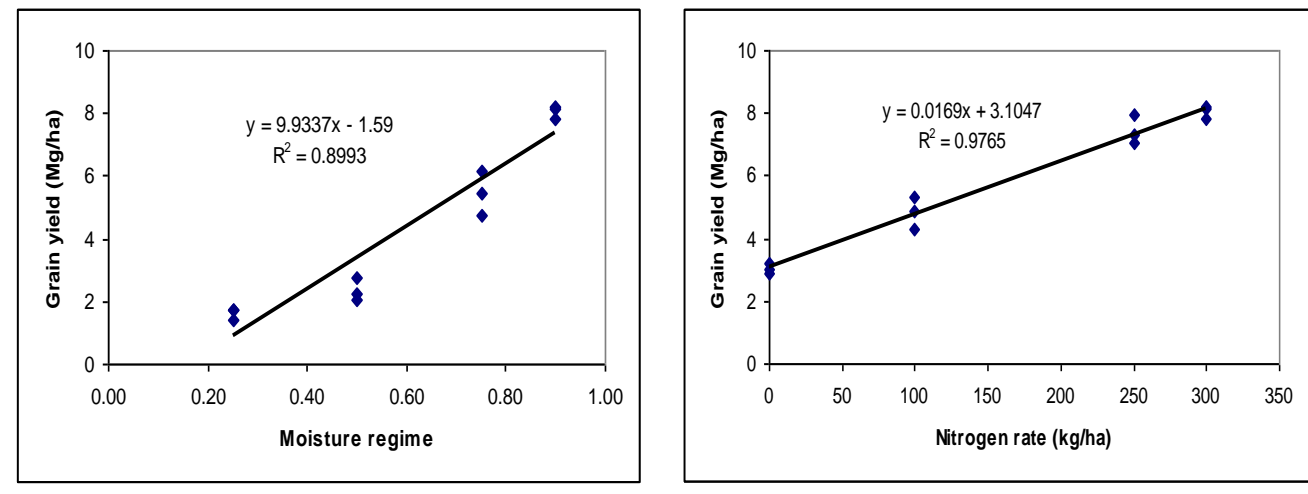

Figure 1 The relationship between maize grain yield and both moisture and nitrogen deficiency stress

\section{Correlation between vegetation indices and maize grain yield}

A total of 15 broad band and hyperspectral vegetation indices demonstrated that some vegetation indices correlated strongly with the measured maize yield. The data collected throughout the growing season was ranked and used to identify the optimum index for predicting maize yield. The results demonstrated that at 30 and 45 days, the coefficient of correlation was nonsignificant $(\mathrm{r}<0.30)$ for all the tested vegetation indices. Table 2 details the coefficient of correlation between different vegetation indices and maize grain yield at different growth stages. At 60 days after sowing, the majority of tested vegetation indices produced significant correlations with the measured yield. The coefficient of correlation increased gradually and reached a maximum value at 90 days after sowing. The results further demonstrated that both hyperspectral and broad band vegetation indices provided similar correlations in most cases. RVI, SAVI, $\mathrm{R}_{750} / \mathrm{R}_{550}$ and OSAVI were found to be the optimum indices for predicting maize yield. Figure 3 illustrates the relationship between RVI and maize grain yield. It is obvious that there is a linear significant relationship between them $\left(\mathrm{R}^{2}=\right.$ 
0.79). These results are in broad agreement with others (Babar et al., 2006; Prasad et al., 2007) demonstrating that crop yield can be predicted before maturation.

However, the work presented here at the canopy scale has shown that the grain filling stage was the optimum stage for predicting grain yield. The results therefore suggest that remote sensing can provide a reliable approach to predict crop yield at relatively early stages enabling appropriate management practices to be implemented to limit crop reductions and thus increase crop productivity. Moreover, the results showed no advantage of using hyperspectral indices over broad band indices which is useful to use high spatial resolution satellite images with low spectral capabilities (e.g. QuickBird or similar platforms) for monitoring agricultural crops status.

Table 2 Coefficient of correlation for the relationship between vegetation indices and maize grain yield at different growth stages. Highlighted values are the strongest correlations

\begin{tabular}{|c|c|c|c|c|c|}
\hline \multirow{2}{*}{ Index } & \multicolumn{5}{|c|}{ Days after sowing } \\
\hline & 30 & 45 & 60 & 75 & 90 \\
\hline NDVI & 0.05 & 0.18 & $0.41 *$ & $0.71 * *$ & 0.83 ** \\
\hline RVI & 0.07 & 0.22 & $0.50 * *$ & $0.73^{* *}$ & $0.89 * *$ \\
\hline SAVI & 0.07 & -0.04 & $0.42 *$ & $0.62 * *$ & 0.89 ** \\
\hline GNDVI & 0.04 & 0.29 & $0.59 * *$ & $0.64 * *$ & 0.83 ** \\
\hline DVI & 0.11 & -0.13 & $0.41 *$ & $0.72 * *$ & 0.88 ** \\
\hline SLAVI & 0.03 & 0.18 & $0.41 *$ & $0.71 * *$ & 0.83 ** \\
\hline OSAVI & 0.07 & 0.01 & $0.42 *$ & $0.72 * *$ & $0.89 * *$ \\
\hline RDVI & 0.02 & 0.16 & $-0.37 *$ & $0.68 * *$ & $-0.85 * *$ \\
\hline SI & 0.06 & 0.21 & $0.48 * *$ & $0.73 * *$ & $0.88 * *$ \\
\hline IPVI & 0.09 & 0.17 & $0.38 *$ & $0.48 * *$ & 0.80 ** \\
\hline $\mathbf{R}_{695} / \mathbf{R}_{760}$ & 0.02 & -0.27 & $-0.47 *$ & $-0.61 * *$ & $0.84 * *$ \\
\hline $\mathbf{R}_{605} / \mathbf{R}_{760}$ & 0.03 & -0.26 & $-0.52 *$ & $-0.58 * *$ & $0.85^{* *}$ \\
\hline $\mathbf{R}_{710} / \mathbf{R}_{760}$ & 0.02 & -0.23 & $-0.50 *$ & $-0.64 * *$ & $0.87 * *$ \\
\hline $\mathbf{R}_{\mathbf{7 5 0}} / \mathbf{R}_{\mathbf{5 5 0}}$ & 0.06 & 0.29 & $-0.60 *$ & $-0.68 * *$ & $0.89 * *$ \\
\hline $\mathbf{R}_{\mathbf{7 5 0}} / \mathbf{R}_{700}$ & 0.01 & 0.20 & $0.58 *$ & $0.72 * *$ & 0.85 ** \\
\hline
\end{tabular}

*Significant at $95 \% \quad * *$ Significant at $99 \%$ 


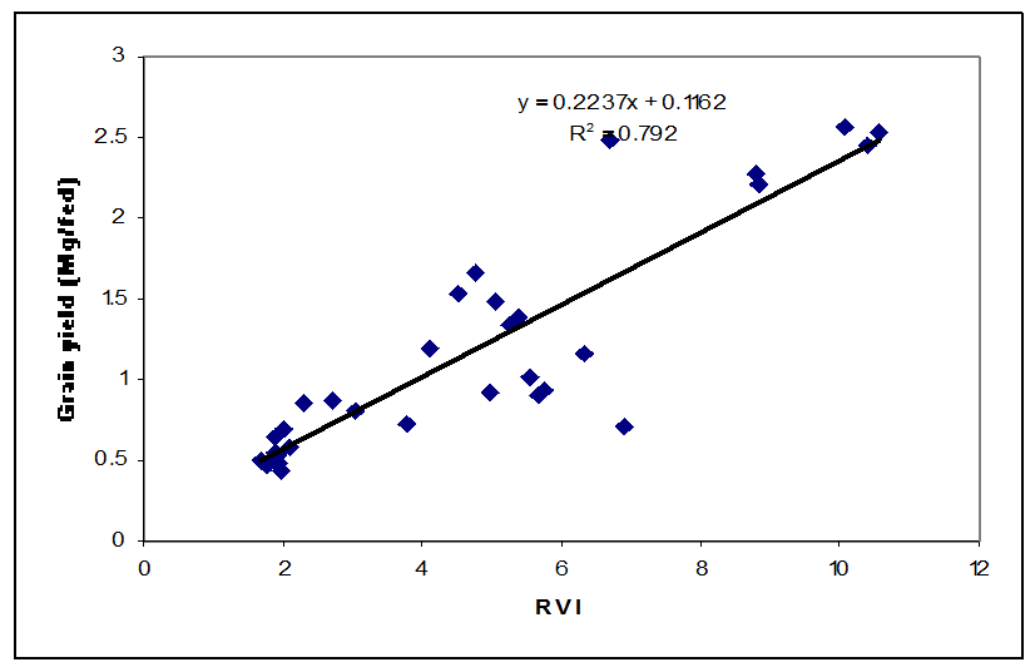

Figure 2 The relationship between RVI derived from hyper spectral measurements and maize grain yield at the flowering stage

\section{Distinguishing between moisture and nitrogen deficiency stresses}

To distinguish between moisture and nitrogen deficiency stresses, the principle component analysis (PCA) was performed on full spectra collected at different growth stages and showed the possibility to distinguish both sources of stress at the flowering and the grain filling stages. As shown in Fig. 3 there is a specific trend for both stressors to plot in separate quarters. The obtained PCA loading plots suggest that reflectance spectra in the visible part of the magnetic spectrum were the most strongly correlated with the level of stress. The NIR part also showed the possibility to distinguish between moisture and nitrogen stresses. To have a clear distinguish between these two stressors, the PDLA was also run on all spectra at different growth stages. The results demonstrated that the spectra collected at the canopy scale showed better distinguish between both stressors which are in agreement with others findings (Wang et al. 2002; Elmetwalli, 2010). The PDLA demonstrated that it was possible to predict the source of stress in maize particularly for the spectra collected at the canopy scale. Table 3 details the results of the PDLA for the spectra collected at the flowering stage. The user's accuracy reached $100 \%$ in five treatments out of eleven and over 50\% in two other treatments. Also, the producer's accuracy reached over $60 \%$ in seven treatments four of those a $100 \%$. The training misclassification rate was 0.098 whilst the prediction misclassification rate was 0.28 . These results obviously demonstrate that the PDLA showed the ability to distinguish most differences between moisture and nitrogen deficiency stresses. The results 
therefore showed the effectiveness of remotely sensed data to distinguish sources of stress (e.g. moisture and nitrogen deficiency) to make better decisions to avoid crop reductions. The new satellite platforms such as VENUS and Hyperion (more than 200 bands) can therefore be used effectively to distinguish sources of stress at a large scale.

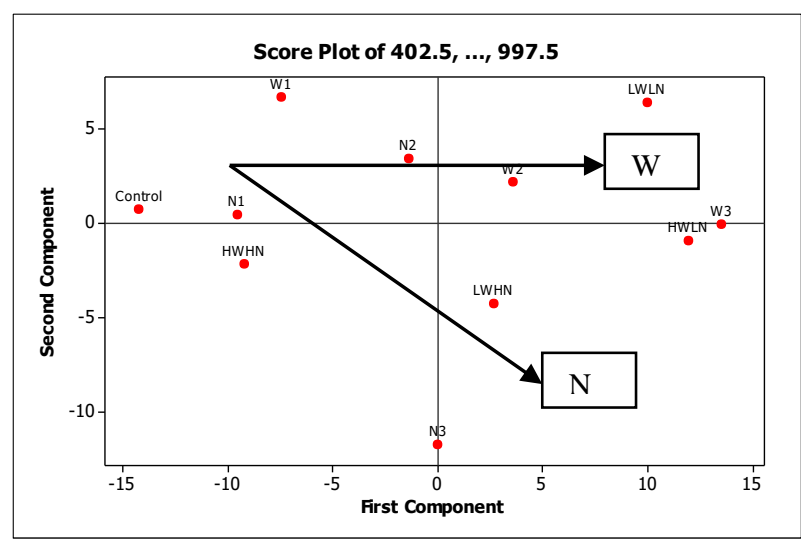

Fig.3 Score plot of PCA for whole spectra collected from control, moisture and nitrogen induced stressed maize canopies at 90 days after sowing $(n=11)$.

Table 3 Confusion matrix for PDLA run on spectra collected from maize subjected to moisture and nitrogen deficiency stresses.

\begin{tabular}{|c|c|c|c|c|c|c|c|c|c|c|c|c|c|}
\hline PDLA & $\mathrm{C}$ & W1 & W2 & W3 & N1 & N2 & N3 & LWHN & LWLN & HWHN & HWLN & Total & $\begin{array}{c}\text { user } \\
\text { accuracy }\end{array}$ \\
\hline $\bar{C}$ & 4 & 1 & 0 & 0 & 4 & 0 & 0 & 0 & 0 & 0 & 0 & 9 & 0.44 \\
\hline W1 & 5 & 6 & 0 & 0 & 0 & 0 & 0 & 0 & 0 & 0 & 0 & 11 & 0.55 \\
\hline W2 & 0 & 0 & 0 & 0 & 0 & 0 & 0 & 0 & 0 & 0 & 0 & 0 & 0.00 \\
\hline W3 & 0 & 0 & 6 & 6 & 0 & 0 & 0 & 4 & 0 & 0 & 0 & 16 & 0.38 \\
\hline N1 & 0 & 0 & 0 & 0 & 7 & 0 & 0 & 0 & 0 & 0 & 0 & 7 & 0.00 \\
\hline $\mathrm{N} 2$ & 0 & 0 & 0 & 0 & 0 & 7 & 0 & 0 & 0 & 0 & 0 & 7 & 1.00 \\
\hline N3 & 0 & 0 & 0 & 0 & 0 & 7 & 8 & 0 & 0 & 0 & 0 & 8 & 1.00 \\
\hline LWHN & 0 & 0 & 0 & 0 & 0 & 0 & 8 & 2 & 0 & 0 & 0 & 2 & 1.00 \\
\hline LWLN & 0 & 0 & 0 & 0 & 0 & 0 & 0 & 0 & 5 & 0 & 0 & 5 & 1.00 \\
\hline HWHN & 0 & 0 & 0 & 0 & 0 & 0 & 0 & 0 & 0 & 4 & 0 & 4 & 1.00 \\
\hline HWLN & 0 & 0 & 0 & 0 & 0 & 0 & 0 & 1 & 2 & 0 & 6 & 9 & 0.67 \\
\hline Total & 9 & 7 & 6 & 6 & 11 & 7 & 0 & 7 & 7 & 4 & 6 & 78 & \\
\hline $\begin{array}{l}\text { Producer's } \\
\text { accuracy }\end{array}$ & 0.44 & 0.86 & 0.00 & 1.00 & 0.64 & 0.00 & 1.00 & 0.29 & 0.71 & 1.00 & 1.00 & & \\
\hline & & ng & $\begin{array}{r}\text { isclass } \\
0.098\end{array}$ & & & & & & & 0. & & & \\
\hline
\end{tabular}

Labels: C-control; W1-W3, high-low available water; N1-N3, high to low nitrogen rates; LWHN-low watering high nitrogen; LWLN-low watering low nitrogen; HWHN-high watering high nitrogen; HWLN-high watering low nitrogen

\section{CONCLUSION}

The effectiveness of hyperspectral and broad band remote sensing data for predicting maize grain yield in response to moisture and nitrogen deficiency stress was investigated in this study. It can be concluded that the flowering 
and grain filling stages are the optimum growth stages of maize to collect reflectance measurements to predict crop yield. The obtained results showed that the RVI and SAVI, OSAVI and $\mathrm{R}_{750} / \mathrm{R}_{550}$ provided the optimum indices for predicting maize yield. The PCA and PDLA showed the potential to distinguish between moisture and nitrogen deficiency stresses. Additionally, hyperspectral data provided no advantage over broad band indices in these predictions. Consequently, broad band satellite-based remote sensing platforms with high spatial and high spectral resolution capabilities would be well suited to predict maize grain yield in semi arid and arid environments. Here the novel potential of using remote sensing was demonstrated to detect nitrogen deficiency as well as moisture induced stress at the leaf and canopy scales.

\section{REFERENCES}

Abdel-Rahman, E. M.; Ahmed, F. B. and Van Dan Berg, M. (2010). Estimation of sugarcane leaf nitrogen concentration using in situ spectroscopy. International Journal of Applied Earth Observation and Geoinformation, 125: 552-557.

Araus, J. L.; Casadesus, J. and Bort, J. (2001). Recent tools for the screening of physiological traits determining yield. P. 59-77. In M.P. Reynolds, J. I. Ortiz-Monasterio and A. Mcnab (Eds.) Application of physiology in wheat breeding. CIMMYT, Mexico.

Babar, M. A.; Reynolds, M. P.; van Ginkel, M.; Klatt, A. R.; Raun, W. R. and Stone, M. L. (2006). Spectral reflectance indices as a potential indirect selection criteria for wheat yield under irrigation. Crop Sci. 46: 578-588.

Banziger, M. and Diallo, A. O. (2004). Progress in developing drought and N stress tolerant maize cultivars for eastern and southern Africa. Pp. 189194 In D.K. Friesen and A.F.E. Palmer (eds). Integrated approaches to higher maize productivity in the new millennium. Proceeding of the $7^{\text {th }}$ eastern and southern Africa regional maize conference, 5-11 February 2002. CIMMYT/KARI, Nairobi, Kenya.

Ciganda, V.; Gitelson, A. and Schepers, J. (2009). Non-destructive determination of maize leaf and canopy chlorophyll content. Journal of Plant Physiology, 166: 157-167.

Daughtry, C. S. T.; Walthall, C. L.; Kim, M. S.; Brown de Colstoun, E. and McMurtrey, J. E. (2000). Estimating corn leaf chlorophyll concentration from leaf and canopy reflectance. Remote Sensing of Environment 74: 229-239.

Elmetwalli, A.M. (2008). Remote sensing as a precision farming tool in the Nile Vally, Egypt. Ph.D Thesis in Environmental Sciences, School of 
Biological and Environmental Sciences, University of Stirling, Stirling, UK.

Elmetwalli, A.H. (2010). The potential of Remotely sensed data to predict wheat yield under moisture and nitrogen defeciency stress. Misr J. Agric. Eng., 27(4): 1823-1835.

Hong, S.-D.; Schepers, J. S.; Francis, D. D. and Schlemmer, M. R. (2007). Comparisons of ground-based remote sensors for evaluation of corn biomass affected by nitrogen stress. Communications in Soil Science and Plant Analysis 38: 2209-2226.

Osborne, L. S., Schepers, J. S., Francis, D. D. and Schlemmer, M. R. (2002). Detecting Phosphorus and Nitrogen Deficiencies in Corn Using Radiance Measurements. Agronomy Journal 94: 1215-1221.

Paolo, E. and Rinaldi, M. (2008). Yield response of corn to irrigation and nitrogen fertilization in a Mediterranean environment. Field Crops Research 105: 202-210.

Prasad, B., Carver, B. F.; Stone, M. L.; Babar, M. A.; Raun, W. R. and Klatt, A. R. (2007). Potential use of spectral reflectance indices as a selection tool for grain yield in winter wheat under Great Plains conditions. Crop Science 47: 1426-1440.

Souza, R. P., Machado, E. C., Silva, J. A. B., Lagoa, A. M. M. A. and Silveira, J. A. G. (2004). Photosynthetic gas exchange, chlorophyll fluorescence, and some associated metabolic changes in cowpea (Vigna unguiculata) during water stress and recovery. Environ. Exp. Bot. 51: 45-56.

Tilling, A. K.; Leary, G. J.; Ferwerda, J. G.; Jones, S. D.; Fitzgerald, G. J.; Rodriguez, D. and Belford, R. (2007). Remote sensing of nitrogen and water stress in wheat. Field Crops Research 104: 77-85.

Wang, D.; Wilson, C. and Shannon, M. C. (2002). Interpretation of salinity and irrigation effects on soybean canopy reflectance in visible and near infrared spectrum domain. International Journal of Remote Sensing 23(5): 811-824.

Weber, V.S.; Araus, J.L.; Cairns, J.E.; Sanchez, C.; Melchinger, A.E. and Orsini, E. (2012). Prediction of grain yield using reflectance spectra of canopy and leaves in maize plants grown under different water regimes. Field Crops Research, 128: 82-90.

Zhang, J. C.; Pu, R.L.; Wang, J.H.; Haung, W.J. Yuan, L. and Luo, J.H. (2012). Detecting powder mildew of winter wheat using leaf level hyperspectral measurements. Computers and electronics in Agriculture, 85: 13-23 


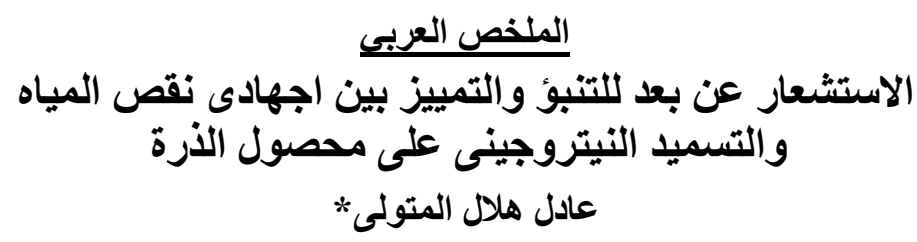

من المعروف أن الاستشعار عن بعد يعتبر تقنية عالية الدقة يعتمد عليها فى الزراعة الدقيقة خلال الربع الاخير من القرن الماضى حيث أظهرت نجاح فى تقدير العديد من الخو اص الطبيعية و الكيميائية

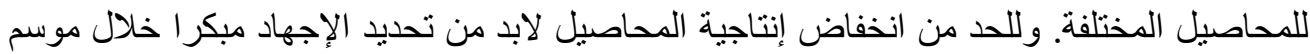

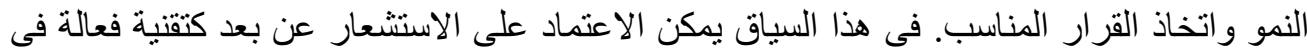

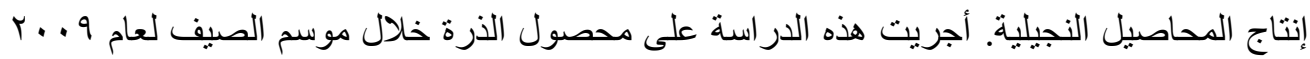

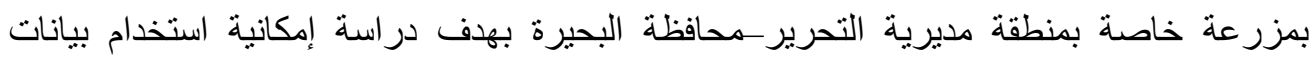

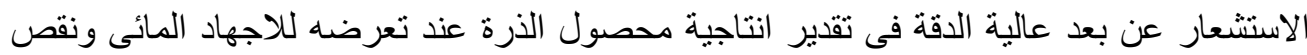

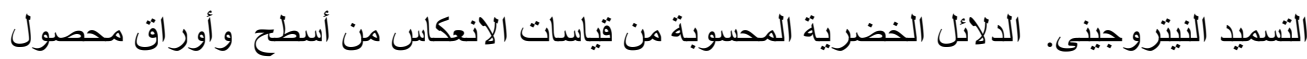

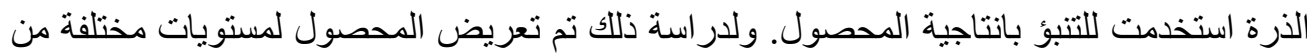

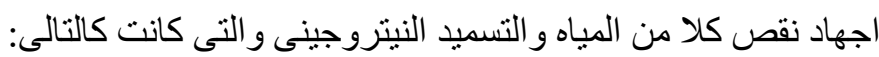

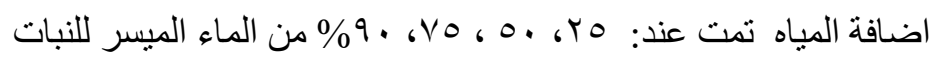

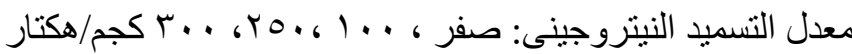

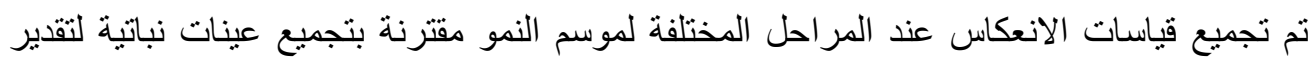
صفاتها المختلفة وفى نهاية الموسم تم تقدير انتاجية المحصول وربط هذه الانتاجية بالدلائل الخضرية الخدية

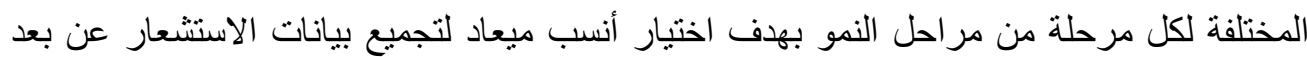

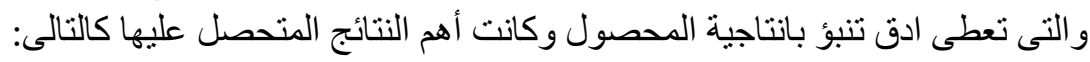

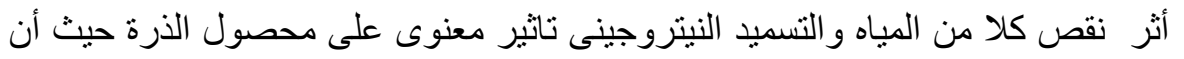

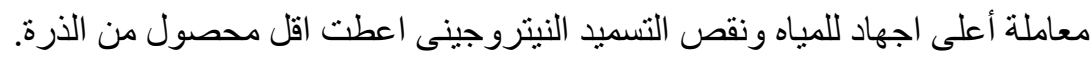

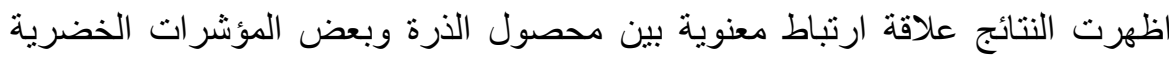
المحسوبة من قياسات الانعكاس. كذلك أظهرت النتائج أن انسب مرحلة نمو لتجميع قياسات الانعكاس من محصول الذرة

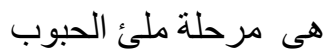
RVI - SAVI - OSAVI - وجد أيضا أن أنسب دلائل خضرية للتنبؤ بانتاجية الذرة هئ $R_{750} / R_{550}$ اظهر تحليل كل من PCA و PLDA امكانية تمييز نقص المياه عن نقص التسميد النيتروجينى. كذلك أظهرت الدر اسة أن استخدام المؤشرات الخضرية المعتمدة فى حسابها على أطو ال موجية محددة (hyperspectral indices) ليس لها ميزة عن المؤشرات الخضرية

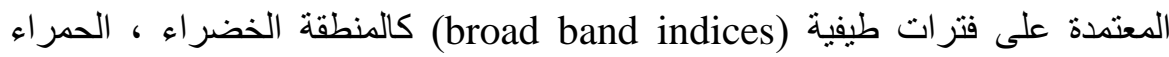
وتحت الحمر اء. وبالتالى فان ذلك يزيد من فرص إمكانية استخدام صور أقمار صناعية ذات عدد محدود من القنو ات الطيفية.

مدرس الهندسة الزراعية ـ قسم الهندسة الزراعية _ كلية الزراعة - جامعة طنطا مصر. 